\title{
Quality of Care Provided by Pediatric Nurses for the Management of Fever in Children
}

\author{
Ghada M. Elseady ${ }^{1}$, Maha I. Khalifa ${ }^{2}$, Omayma M. Okby ${ }^{3}$, Neanaa \\ M. Fayed ${ }^{4}$ \\ ${ }^{1}$ Assistant Lecturer of Pediatric Nursing, ${ }^{2,3}$ Professor of Pediatric Nursing, \\ ${ }^{4}$ Assistant professor of Pediatric Nursing, Faculty of Nursing, Menoufia \\ University
}

\begin{abstract}
Background: Fever is a common childhood health problem faced by health care personnel including doctors, nurses and others in both hospitals and community settings. Lack of knowledge and the presence of conflicting information regarding management of children having fever influences the quality of care and children's health. Purpose: To assess nurses' knowledge and practices regarding management of fever in children. setting: The study was conducted in Pediatric Medical Department and Pediatric intensive care unit in Menoufia University Hospital. Design: A descriptive research was utilized to conduct the study. Sample: All nurses (48 nurses) who were working in the previously mentioned settings were included in this study. Instruments: Two instruments were used. Instrument one was a structured interviewing questionnaire. Instrument two was nurses' clinical performance observational checklist. Results: Two thirds of nurses $(64.4 \%)$ had unsatisfactory knowledge about fever. Also, all nurses had low level of practice regarding fever management. Conclusion: Nurses had unsatisfactory level of knowledge and low level of practices regarding management of fever in children. Recommendation: The study recommended that there was a serious need for improvement of nurses' knowledge and practices in relation to fever management in children.
\end{abstract}

Key words: Pediatric nurses, Children, Fever, Quality of care

\section{Introduction}

Childhood fever is the second most common reason for a child being admitted to hospital. Fever is often an indication of a self-limiting viral infection rather than bacterial or serious illness. However, each year 100 infants aged one to 12 months die from infection and it is likely this number could be reduced by improved recognition, evaluation and treatment of febrile illness (NICE, 2013).

Fever in children can be a diagnostic challenge for health care professionals because it is often difficult to identify the cause. In most cases, the illness is due to a selflimiting viral infection. However, fever may also be the presenting feature of serious bacterial infections such as meningitis or pneumonia. A significant number of children have no obvious cause of fever despite careful assessment. So, these children with fever without apparent source are of particular concern to health care professionals because it is especially difficult to distinguish between simple viral illnesses and life-threatening bacterial infections in this group. As a result, there is a perceived need to improve recognition, assessment and immediate treatment of feverish illness in children. Therefore, National Institute for Health and Clinical Excellence (NICE) developed traffic light system for predicting the risk of serious illness 


\section{Quality of Care Provided by Pediatric Nurses for the Management of Fever in Children}

by assessing feverish children for the presence or absence of particular signs and symptoms (NICE, 2019).

Although, the disease process that leads to fever may be harmful, there is no evidence to demonstrate that fever itself is harmful. In fact, the presence of fever inhibits bacterial growth and the replication of viruses. Many children tolerate mild to moderate fever with remarkable ease. Fever has many immunological benefits, however, it is often viewed negatively by parents and nurses and treated aggressively (Greensmith, 2013).

Moreover, there is no evidence that fever itself worsens the course of illness or that it causes long term neurologic complications such as brain damage, febrile convulsion and death. Thus, the primary goal of treating the febrile child should be to improve the child's overall comfort rather than focus on the normalization of body temperature (Sullivan \& Farrar, 2011).

Knowledge of fever management is inconsistent across studies from different countries. Incorrect beliefs among nurses toward fever and the role of antipyretics still exist. Parents and health care providers did not have enough knowledge for dealing with febrile child and have concerns about complications of fever management. These concerns and knowledge deficit affect negatively on parental and health care providers practices for managing febrile child. Knowledge deficit may be barriers to communicating or discussing nursing practices with doctors to provide better care for febrile children (Tran, 2014).

Specific nursing interventions aimed at reducing child's temperature will not affect the outcome of the underlying illness. So, the primary interventions when caring for febrile children include supporting body's natural physiological response, increasing fluid intake and improving the child's comfort (Patricia, 2014).

Pediatric nurses play a crucial role in the management of fever in children being both the first responder to the detection of child with fever in the inpatient setting and an educator to families of evidence- based best practice for fever management (Clark, 2019). Nurses are involved in the care of a child at every step from triage to hospitalization. Accurately measuring temperature of a child is key to determining further appropriate management in children (Allen, 2020).

Pediatric nurses cannot educate families about fever management if they do not have sufficient knowledge related to fever. So, pediatric nurses should have sufficient knowledge related to fever management in order to educate families about fever management (Greensmith, 2013). For this reason, the purpose of this study was to assess nurses' knowledge and practices regarding management of fever in children.

\section{Purpose}

The purpose of this study was to assess nurses' knowledge and practices regarding management of fever in children.

\section{Research questions:}

1. What is nurses' knowledge level regarding fever management?

2. What is nurses' practice level regarding fever management?

\section{Methods}

Research Design: A descriptive research design was used in this study. 


\section{Quality of Care Provided by Pediatric Nurses for the Management of Fever in Children}

Research Setting: This study was conducted at Pediatric Medical Department and Pediatric Intensive Care Unit in Menoufia University Hospital. Pediatric Medical Department contained 4 rooms in the $4^{\text {th }}$ floor. The first three rooms were for children with different diagnoses. The last fourth room was for children with thalassemia receiving blood transfusion. Each room contained 8 beds. Pediatric Intensive Care Unit was one large room in the $4^{\text {th }}$ floor. It contained 10 beds.

Sampling: All nurses providing care for children in Pediatric Medical Department and Pediatric Intensive Care Unit were included in this study (48 nurses). The number of studied nurses at Pediatric Medical Department and Pediatric Intensive Care Unit in Menoufia University Hospital was 18 and 30 respectively.

\section{Instrument:}

Two instruments were utilized for data collection:

\section{Instrument one: Structured Interviewing Questionnaire:}

It is a structured interview questionnaire. It was developed by the researchers guided by Walsh et al., (2005) after reviewing literature. It was designed to collect data about nurses' social characteristics, knowledge about fever and its nursing care. It was divided into three parts $(\mathrm{a}=0.951)$.

1. Part one: Social characteristics of studied nurses. It included questions about age, gender, level of education, years of experience and training courses.

2. Part two: Nurses' knowledge about fever. It included 21 items about definition of fever, normal range of body temperature, types of thermometers, methods of measuring temperature, benefits of fever and its complications, etc.

3. Part three: Nurses' knowledge about nursing care related to fever. It included 24 items about when to administer antipyretic drugs, route of administration, dosage of antipyretics, purpose of giving antipyretics, recommended water temperature for lukewarm bath, side effects and precautions for acetaminophen, etc.

The Total Scoring System of Nurses' Knowledge about Fever:

\begin{tabular}{|c|c|}
\hline Level of knowledge & Score \\
\hline Unsatisfactory $\leq 60 \%$ & $0-25$ \\
\hline Satisfactory & $26-42$ \\
\hline
\end{tabular}

The Total Scoring System of Nurses' Knowledge about Nursing Care related to Fever:

\begin{tabular}{|c|c|c|}
\hline \multicolumn{2}{|c|}{ Level of knowledge } & \multirow{2}{*}{$\begin{array}{l}\text { Score } \\
0-29\end{array}$} \\
\hline Unsatisfactory & $\leq 60 \%$ & \\
\hline Satisfactory & $>60 \%$ & $30-48$ \\
\hline
\end{tabular}

Instrument two : Nurses' Clinical Performance Observational Checklist: -

It was developed by researchers to observe nursing management of fever. It was divided into three parts $(a=0.921)$

1. Part one: Immediate assessment on child admission. It included checking the child for immediate life-threatening signs, measuring child's body temperature and assessing child using traffic light system.

2. Part two: Management of children with fever. It included physical interventions and antipyretic interventions. Physical interventions included giving the child cooling drinks, keeping room ventilated, removing extra blankets and clothing, keeping child in light 


\section{Quality of Care Provided by Pediatric Nurses for the Management of Fever in Children}

clothing, feeding if he or she is hungry and bathing child with lukewarm bath. Antipyretic interventions included evaluating children before medication and administering antipyretic medication if temperature is greater than $39{ }^{\circ} \mathrm{C}$ and associated with discomfort.

3. Part three: Documentation and advice for home care. It included documentation of temperature, child's behavior, overall condition of the child and antipyretic administration. Advice for home care included giving regular fluids, monitoring for signs of dehydration, removing extra clothes, giving the child paracetamol only if he is distressed, keeping the child away from nursery or school, checking the child during night and when to seek further help.

The Total Scoring System of Nurses' Practices about fever:

\begin{tabular}{|l|c|}
\hline Scoring items & Score \\
\hline $\begin{array}{l}\text { Not Done } \\
60 \%\end{array}$ & $0-33$ \\
\hline Done >60\% & $34-53$ \\
\hline
\end{tabular}

For validity assurance, the two instruments were submitted to a jury of five experts in the pediatric field (three professors in Pediatric Nursing and two professors in Pediatric Medicine) to modify any required items of the instruments. All required modifications were done.

\section{Ethical considerations}

Approval of the Faculty of Nursing in Menoufia Ethical Research Committee was obtained. A written consent was obtained from nurses related to their acceptance to share in the study after an initial interview was done to inform the nurses about the purpose and methods of data collection to gain their cooperation. They were assured that the information collected would be treated confidentiality and that it would be used only for the purpose of research. They were informed that their participation in the study was voluntarily and the participants could withdraw from the study at any time.

\section{Pilot study:}

After the instruments were developed and before starting data collection, a pilot study was carried out on $10 \%$ of the total sample (five nurses) to test the applicability, consistency, practicability, clarity and the feasibility of the study instruments and to estimate the needed time to fill the instruments. The results of the data obtained from the pilot study helped in the modification of the study instruments where some items were added as necessary. The researcher added steps of measuring child's body temperature using mercury glass thermometer. All nurses involved in the pilot study were excluded from the study sample.

\section{Procedure}

1. A written permission to carry out the study was obtained from the director of Menoufia University Hospital after submitting an official letter from the Dean of the Faculty of Nursing at Menoufia University explaining the purpose of the study and methods of data collection.

2. Data collection for this study was conducted for a period of 6 months extending from the first of January to the end of June 2020.

3. The researchers introduced themselves to nurses who participated in the study, explained the purpose of study and methods of data collection. 


\section{Quality of Care Provided by Pediatric Nurses for the Management of Fever in Children}

4. The researchers interviewed every nurse and asked her to fill the structured interviewing questionnaire about fever and its nursing care by using instrument one within 20 minutes.

5. Instrument two was used by the researchers for data collection about nurses' practices during providing care for children with fever. Nurses were not informed that they were observed three days per week during the morning and afternoon shifts.

\section{Statistical analysis:}

Data was coded and transformed into specially designed form to be suitable for computer entry process. Data was entered and analyzed by using SPSS (Statistical Package for Social Science) statistical package version 22. Graphics were done using Excel program. Data were presented in tables in the form of numbers and percentages. Mean and standard deviation Chi-square test was used to estimate the statistical significant differences between variables of study.

\section{Results}

Table 1 represented percentage distribution of studied nurses according to their social characteristics. The table showed that more than half of studied nurses $(58.3 \%)$ were $20-<30$ years with mean age $25.1 \pm 2.3$ years. Regarding gender of studied nurses, the majority of studied nurses (85.4\%) were females. In relation to nurses' qualifications, less than half of studied nurses $(45.8 \%)$ had nursing diploma. Regarding years of experience, less than half of studied nurses $(41.6 \%)$ had $>10$ years of experience. concerning training courses, the majority of studied nurses $(79.2 \%)$ did not attend any training courses on caring of children with fever.

Table 2 illustrated level of total nurses' knowledge about fever in children. This table revealed that two thirds of nurses (64.6\%) had unsatisfactory level of knowledge regarding fever in children.

Table 3 illustrated distribution of nurses according to their practices regarding fever management in children. It was clear that all nurses had low level of practice regarding fever management in children.

Table 4 illustrated correlation between the studied nurses' sociodemographic characteristics and their total knowledge level. The table clarified that there was highly statistically significant difference between nurses' knowledge and educational level while no statistical significant differences regarding age, experiences and training courses were found.

\section{Results}

Table (1): Percentage distribution of studied nurses according to their social characteristics $(n=48)$. 
Quality of Care Provided by Pediatric Nurses for the Management of Fever in Children

\begin{tabular}{|c|c|c|}
\hline Social characteristics of studied nurses & No & $\%$ \\
\hline \multicolumn{3}{|l|}{ Age (Years) } \\
\hline$<20$ years & 3 & 6.3 \\
\hline $20-<30$ & 28 & 58.3 \\
\hline $30-<40$ & 11 & 22.9 \\
\hline$\geq 40$ years & 6 & 12.5 \\
\hline Mean \pm SD & \multicolumn{2}{|c|}{$25.1 \pm 2.3$ years } \\
\hline \multicolumn{3}{|l|}{ Gender: } \\
\hline Male & 7 & 14.6 \\
\hline Female & 41 & 85.4 \\
\hline \multicolumn{3}{|l|}{ Qualifications: } \\
\hline Nursing Diploma & 22 & 45.8 \\
\hline Technical Institute of Nursing & 21 & 43.8 \\
\hline Bachelor & 5 & 10.4 \\
\hline \multicolumn{3}{|l|}{ Years of experience } \\
\hline$<1$ year & 2 & 4.2 \\
\hline $1-<5$ years & 13 & 27.1 \\
\hline $5-<10$ years & 13 & 27.1 \\
\hline$\geq 10$ years & 20 & 41.6 \\
\hline \multicolumn{3}{|l|}{ Training courses } \\
\hline No & 38 & 79.2 \\
\hline Yes & 10 & 20.8 \\
\hline Total & 48 & 100 \\
\hline
\end{tabular}

Table (2): Levels of Total Nurses' Knowledge about Fever in Children.

\begin{tabular}{|l|c|c|}
\hline Knowledge items & No & $\%$ \\
\hline Unsatisfactory knowledge & 31 & $64.6 \%$ \\
Satisfactory knowledge & 17 & $35.4 \%$ \\
\hline Total & 48 & $100.0 \%$ \\
\hline
\end{tabular}

Table (3) Distribution of Nurses According to their Practices Regarding Fever Management in children.

\begin{tabular}{|l|c||c|}
\hline Practices items & N0 & \% \\
\hline \hline Not done & 48 & $100.0 \%$ \\
Done & 0 & $0.0 \%$ \\
\hline \hline Total & 48 & $100.0 \%$ \\
\hline
\end{tabular}

Table (4): Correlation between the studied nurses 'social characteristics and their total knowledge level. 


\begin{tabular}{|c|c|c|c|c|c|c|c|c|}
\hline \multirow{3}{*}{\multicolumn{2}{|c|}{$\begin{array}{l}\text { Total knowledge } \\
\begin{array}{l}\text { Socio-demographic } \\
\text { characteristics }\end{array}\end{array}$}} & \multirow{4}{*}{$\begin{array}{c}\text { Total } \\
\text { N0. } \\
3 \\
\end{array}$} & \multicolumn{6}{|c|}{ Knowledge levels } \\
\hline & & & \multicolumn{2}{|c|}{$\begin{array}{c}\text { Unsatisfactory } \\
\text { know. }\end{array}$} & \multicolumn{2}{|c|}{$\begin{array}{c}\text { Satisfactory } \\
\text { know. }\end{array}$} & \multicolumn{2}{|c|}{ Chi-square } \\
\hline & & & No & $\%$ & No & $\%$ & $\mathbf{X}^{2}$ & P-value \\
\hline \multirow{4}{*}{ Age (years) } & $<20$ years & & 2 & 66.7 & 1 & 33.3 & \multirow{4}{*}{$X^{2}=3.7$} & \multirow{4}{*}{$0.30 \mathrm{NS}$} \\
\hline & $20-<30$ years & 28 & 21 & 75 & 7 & 25 & & \\
\hline & $\begin{array}{c}30-<40 \\
\text { years }\end{array}$ & 11 & 5 & $45.5 q$ & 6 & 54.5 & & \\
\hline & $\geq 40$ years & 6 & 3 & 50 & 3 & 50 & & \\
\hline \multirow{2}{*}{ Gender } & Male & 7 & 2 & 28.6 & 5 & 71.4 & \multirow{2}{*}{$X^{2}=4.6$} & \multirow{2}{*}{$0.03 \mathrm{Sig}}$. \\
\hline & Female & 41 & 29 & 70.7 & 12 & 29.3 & & \\
\hline \multirow{3}{*}{ Education } & Diploma & 22 & 15 & 68.7 & 7 & 31.8 & \multirow{3}{*}{$\mathrm{LR}=11.8$} & \multirow{3}{*}{$0.005 \mathrm{HS}$} \\
\hline & Institute & 21 & 16 & 76.2 & 5 & 23.8 & & \\
\hline & Bachelor & 5 & 0 & 0 & 5 & 100 & & \\
\hline \multirow{4}{*}{ Experiences } & $<1$ year & 2 & 2 & 100 & 0 & 0 & \multirow{4}{*}{$\mathrm{LR}=1.9$} & \multirow{4}{*}{$0.60 \mathrm{NS}$} \\
\hline & $1-<5$ years & 13 & 8 & 61.5 & 5 & 38.5 & & \\
\hline & $5-<10$ years & 13 & 8 & 61.5 & 5 & 38.5 & & \\
\hline & $\geq 10$ years & 20 & 13 & 65 & 7 & 35 & & \\
\hline \multirow{2}{*}{ Training courses } & No & 38 & 25 & 65.8 & 13 & 34.2 & \multirow{2}{*}{ Fisher } & \multirow{2}{*}{$0.72 \mathrm{NS}$} \\
\hline & Yes & 10 & 6 & 60 & 4 & 40 & & \\
\hline Total & & $\overline{48}$ & 31 & 64.6 & 17 & 35.4 & & \\
\hline
\end{tabular}

$\mathrm{NS}=$ No statistical significance $(\mathrm{P}>0.05) \mathrm{HS}=$ High significant $\quad \mathrm{LR}=$ Likelihood Ratio Fisher= Fisher exact test.

\section{Discussion}

Childhood fever is a common occurrence and often a grave concern to parents. Misconceptions and unfounded fears regarding fever exist among parents and pediatric providers a like, despite the evidence that fevers are not harmful in most circumstances. In addition. Fear of fever can lead to aggressive and dangerous practices including overdosing with antipyretics and sponge bathing with alcohol. Therefore, pediatric nurses need to understand the physiology of the febrile response and upgrade their practices in relation to evidence- based fever management for their children (Patricia, 2014).

The findings of the present study showed that two thirds of nurses had unsatisfactory knowledge about fever in children. This finding agreed with Gouda et al., (2019) who conducted a study about "Nurses' knowledge and practices regarding to fever management of neonates". They indicated that the majority of nurses had unsatisfactory knowledge regarding to fever management of neonates. This might be due to the absence of in-service training programs about fever management and the absence of formal hospital policies for fever management. Also, this finding agreed with Greensmith (2013) who conducted a study about "Nurses' knowledge and attitudes toward fever and fever management in one Irish Hospital". The study identified that pediatric nurses were not expert fever managers and their knowledge deficits as well as their negative attitudes influenced their practices.

The results showed that three quarters of nurses had incorrect answers about normal range of body temperature and definition of fever in children. This result was consistent with Khalifa 


\section{Quality of Care Provided by Pediatric Nurses for the Management of Fever in \\ Children}

(2007) who conducted a study about "Impact of an educational program based on evidence related to fever management". It was found that nurses were unable to identify the exact definition of fever, its mechanism of action, differentiate between different levels of hyperthermia or associated signs that necessitate calling an emergency for help. Furthermore, this finding was consistent with Thompson \& Kang (2012) who conducted a study about "Clinical management of fever by nurses" and showed that the majority of nurse participants could not distinguish hyperthermia from fever. From the researcher's point of view, nurses' incorrect definition of fever may be influenced by the inconsistent references and information they received. Another reason could be that the majority of nurses did not receive training courses about mechanism of fever and its management.

Moreover, the results indicated that more than half of studied nurses had incomplete knowledge about physiology of fever. Such finding agreed with Mohamed \& Ali (2012) who conducted a study about "Critical care nurses' knowledge and practices of fever management at a University Hospital". They reported that all critical care nurses had unsatisfactory knowledge scores about physiology of thermoregulation and pathophysiology of fever. This could reduce nurses' abilities in relation to preserving core body temperature balance. On the contrary, this finding was inconsistent with Rabee (2018) who conducted a study about 'Nurses' knowledge, attitude and practices in the management of childhood fever in emergency department at governmental hospitals at Gaza Strip" who found that more than three quarters of the participants $(84 \%)$ knew the pathophysiology of fever. This could be attributed to differences in data collection settings as well as different nurses' backgrounds.

In addition, the results indicated that the majority of nurses had incorrect answer about the most common side effects of fever in children. This finding was in agreement with Tran (2014) who conducted a study about "Fever management in children: Vietnamese parents' and pediatric nurses' knowledge, beliefs and practices". Findings of the study showed that nurses were unaware that the most common side effect of fever is dehydration.

The findings showed that all nurses had low level of practice regarding fever management in children. This may be due to that all nurses had misconceptions about fever and the hospitals did not provide them with needed supplies. This result was consistent with Gouda et al., (2019) who found that two thirds of studied nurses had incompetent level of practice. Also, this result was supported with Khalifa (2007) who reported that incorrect practices related to fever management was recorded. This was reflected by their continuing use of cold compresses, application of alcohol and vinegar on skin of feverish children and frequent administration of cold water showers to feverish children.

The results showed that none of nurses measured axillary temperature by using digital thermometers because they were not available in the hospital and expensive. This result was consistent with Zubedeh et al., (2016) who conducted a study about 'Physicians and nurses' knowledge, attitude and practices in the management of childhood fever in Hebron pediatric clinics". They found that only $28 \%$ of physicians and nurses were using electronic thermometers. Also, the results indicated that none of 


\section{Quality of Care Provided by Pediatric Nurses for the Management of Fever in \\ Children}

nurses assessed the child by using traffic light system. This result may be due to the fact that nurses from their point of view considered that this was not their responsibility but it was the doctors' responsibility. Also, this result might be due to lack of nurses' knowledge about traffic light system. This finding was consistent with Mohamed \& Ali (2012) who found that all participants in the studied sample did not assess the presence of chills, diaphoresis, dryness of mucous membrane and skin turgor.

Moreover, the results indicated that all nurses did not perform documentation and advice for home care. This result came in line with Zubedeh et al., (2016) who demonstrated that nurses do not provide enough education about fever and fever management practices.

The findings showed that there was highly statistically significant difference between nurses' knowledge and their educational levels. This result was consistent with Gouda et al., (2019) who showed that there was highly statistically significant difference between nurses' knowledge and educational levels. From the researchers point of view this can be interpreted as Bachelor nurses have scientific knowledge about physiology of fever and thermoregulation.

\section{CONCLUSION}

Based on the results of the present study, it was concluded that pediatric nurses had unsatisfactory level of knowledge and low level of practice regarding fever management in children and need in-service training about evidence- based fever management to improve their knowledge and practices regarding fever management in children.

\section{Recommendations}

Based on study findings and conclusion the following were recommended:

- Ongoing in-service education programs about evidence-based childhood fever management should be designed and implemented in pediatrics department and pediatric intensive care units to improve pediatric nurses' knowledge and practices.

- The hospitals should provide nurses with the required supplies to demonstrate evidence-based fever management.

- Newly appointed nursing staff members who provide care for children with fever in pediatrics departments and pediatric intensive care units should be skilled in following standardized evidencebased protocols for fever management.

- Replication of study on a larger sample of nurses obtained from different geographical areas in Egypt.

\section{References}

Allen, C. (2020). Fever without a source in children 3 to 36 months of age. Up To Date. Waltham, MA.

Clark, S. (2019). Management of Fever in Children: Realities of Nursing Practice. Doctoral dissertation. The University of Auckland. https://researchspace. auckland.ac.nz/docs/uoadcs/rights.htm.

Gouda, S. S., Ouda, W. E., Adly, R. M. \& Tantawi, H. R. (2019). Nurses' knowledge and practices regarding to fever management of neonates. 
Egyptian Journal of Healrh Care ,3(3), 31-40.

Greensmith, L. (2013). Nurses' knowledge of and attitudes toward fever and fever management in one Irish children's hospital. Journal of Child Health Care, 17(3).305-316.

Khalifa, M. I. (2007). Impact of an educational program based on evidence related to Fever management. The Journal of the Egyptian Public Health Association, 82(5-6), 419-435.

Mohamed, L., \& Ali, N. S. (2012). Critical Care Nurses' Knowledge and Practice of Fever Management at a University Hospital. Journal of American Science, 8(12).15451553.

http://www.jofamericanscience.or g.

National Institute of Health and Care Excellence (NICE) (2013). Feverish illness in children: Assessment and initial management in children younger than 5 years. Available at: http://publications.nice.org.uk/feve rish-illnessinchildren-cg160.

National Institute for Health and Care Excellence (NICE). (2019). Fever in under 5s: Assessment and initial management.

(UK);(NICE Guideline, No.143). http://www.ncbi.nlm.nih/books/N BK552086/.=

Patricia, C. (2014). Evidence-based management of childhood fever: what pediatric nurses need to know. Journal of pediatric nursing,
29(4),

372-375. https://doi.org/10.1016/j.pedn.201 4.02.007.

Rabee, M. S. (2018). Nurses' knowledge, Attitude and Practices in the Management of Childhood Fever in Emergency Departments at Governmental Hospitals in Gaza Strip. Master thesis. Deanship of Graduate Studies. AlQuds University.

Tran, T. K. L. (2014). Fever management in children: Vietnamese parents' and pediatric nurses' knowledge, beliefs and practices. Doctoral dissertation, Queensland University of Technology.

Sullivan, J. E., \& Farrar, H. C. (2011). Fever and antipyretic use in children. Pediatrics, 127(3),580587. https://doi.org/10.1542/peds.20103852 .

Thompson, H. J., \& Kagan, S. H. (2012). Clinical management of fever by nurses: doing what works. Journal of advanced nursing, 67(2), 359-370. https://doi.org/10.1111/j.13652648.2010.5506.x.

Zubedeh, M., Mayaleh, A., Qtait, M., \& Sayej, S. (2016). Physicians and Nurses Knowledge, Attitude, and Practices in the Management of Childhood Fever in Hebron Pediatric Clinics. Journal of Health, Medicine and Nursing, 13, ISSN 2422-8419. http://www.resarchgate.net/public ation/312039524. 